\title{
Introduction to the special issue on the dynamics of written word production: methods, models and processing units
}

\author{
Eric Lambert ${ }^{1} \cdot$ Pauline Quémart ${ }^{1}$
}

Published online: 18 December 2018

(c) Springer Nature B.V. 2018

\begin{abstract}
During the three past decades, written production models were essentially aimed at proposing a static view of the processes implemented to produce words. However, there are an increasing number of studies with the aim of better understanding the dynamics of the course of the writing process. These studies have raised a number of issues regarding the method used to study written word production and the factors that influence the dynamics of writing (type of orthography, transparency of the orthography, level of development, etc.). The scope of this special issue is to advance knowledge of the dynamics of written word production through empirical studies that address the above issues. This issue is based on the first Writing Word(s) Workshop (W3), which took place in July 2015 in Poitiers, France. The issue contains 9 articles by leading scholars in the field of the dynamics of written word production.
\end{abstract}

Keywords Writing $\cdot$ Word $\cdot$ Handwriting $\cdot$ Real time

In this twenty-first century, writing is an essential part of our society, and it is the primary means of communication. Many of our daily activities are mediated by our written products, both in the private sphere (internet, personal diary, etc.) and in the public sphere (administrative process, memorandum, etc.; Bazerman, 2009). Over the last two decades, an increasing number of scientific articles have been dedicated to writing, but the number of studies is still far below those of oral language and reading. For example, in 2007, we identified 24 papers focused on reading in the "Reading and Writing" Journal, while the number of articles on writing was 7 (22\% of the total number of articles published in the journal that year). Ten years later, in 2017, we found 44 articles devoted to reading research and 22 to writing (33\% of the

Eric Lambert

eric.lambert@univ-poitiers.fr

1 Centre de Recherches sur la Cognition et l'Apprentissage (UMR 7295), Université de Poitiers and French National Centre for Scientific Research (CNRS), 5 rue Théodore Lefebvre, TSA 21103, 86073 Poitiers Cedex 9, France 
total number of articles published in the journal that year) in this journal. Even if the gap is narrowing, there is always an imbalance between these two fields of research. In addition, writing research focuses mainly on the issue of instruction and school applications, and few studies concern the question of the mechanisms underlying the written production of words, especially isolated words. However, the study of cognitive processes involved in either oral production or word recognition is a very active field of research. It is indeed fundamental to understand precisely the mechanisms by which isolated words are processed before we understand what is involved in sentence processing. A final important point to note is that no research-focused event has ever focused on the word writing issue.

Based on these observations, in 2015, the first Writing Word Workshop (W3) was organized at the University of Poitiers (France). This workshop was the first in a series of biennial events organized in different universities; the second W3 was held in 2017 at the University of Bristol (UK). The first W3 brought together 35 researchers recognized in the field of written word production across different labs and countries. The present special issue is the continuation of this workshop. It gathers 9 articles on the most recent studies in the field of word writing. This special issue is organized around five major research questions.

\section{Which methodology for studying written word production?}

The first studies on writing words (i.e., the studies conducted in the 1980-1990s) were based on an offline methodology, i.e., the analysis of the finished product with a particular focus on spelling errors. These studies made significant progress in understanding the processes implemented during written word production (Ellis, 1979; Henderson \& Beers, 1980). Nevertheless, focusing on errors (whether in terms of quantity or quality) does not directly inform us about the mechanisms involved in correct word spelling. Therefore, the combination of offline methodology with real-time analysis makes it possible to study not only the finished product but also the dynamics of writing. Real-time analyses are made possible thanks to the development of digitizing tablets associated with spatiotemporal recording software for handwriting, such as Ductus (Guinet \& Kandel, 2010), Eye and Pen (Alamargot, Chesnet, Dansac, \& Ros, 2006) or MovAlyzeR ${ }^{\circledR}$ (Neuroscript, 2018). Technical advances now allow time recordings with an accuracy of 5 to $6 \mathrm{~ms}-$ a level of precision very close to that of software used to study word recognition, such as E-Prime, Psychopy or DMDX — and with a spatial accuracy of approximately $0.2 \mathrm{~mm}$.

Early studies using real-time analyses were largely inspired by studies conducted in oral and written word recognition. The studies therefore focused on reaction time, i.e., the time between the presentation of the stimulus and the start of writing. These studies have used different paradigms, such as masked priming (e.g., Bonin, Fayol, \& Peereman, 1998), the picture-picture priming paradigm (e.g., Roux \& Bonin, 2011) or, even more simply, picture naming (Zhang \& Wang, 2015).

However, focusing only on reaction times could mask effects that occur during word writing. Word writing is relatively slow compared to word reading or oral word production, which allows for parallel activation of cognitive and motor 
processes (Afonso \& Alavarez, in press; for a general view on writing, from text production to word production, see Olive, 2014). Speech has an average delivery rate of 200 words per minute, while the writing delivery rate is approximately 30 words per minute. Focusing only on the time window preceding the writing is thus likely to mask later effects occurring in parallel with handwriting. Therefore, not taking into account variations of writing duration greatly reduces understanding of the processes involved in written word production. For example, item lexicality and orthographic regularity influence not only writing latency but also writing dynamics (Roux, McKeeff, Grosjacques, Afonso, \& Kandel, 2013). Irregular words are initialized more slowly but also have a slower writing speed than regular words (Delattre, Bonin, \& Barry, 2006). Similarly, orthographic regularity influences not only writing speed but also writing fluency (Kandel \& Perret, 2015). There is now evidence that central processes interact with peripheral processes, so it is important to take into account all temporal variables.

This special issue has combined articles using different methods in order to show the importance of methodology choice in highlighting the processes involved in written word production. First, the studies reported here differ in the measurement carried out during written word production. Most of these studies have measured writing latency (Afonso, Alvarez, Martinez, \& Cuetos; Bonin, Méot, Laroche, Bugaiska, \& Perret; Breining \& Rapp; Damian \& Qu; Kandel, Peereman, Ghimenton, Perret; Planton, Juda, Démonet, Soum-Favaro; Quémart \& Lambert; Ronnenberg \& Torrance), which is coupled in several studies with temporal indicators related to handwriting, such as letter writing duration and writing speed (Kandel et al., Planton et al., Quémart \& Lambert), inter-letter interval duration (Afonso et al., Kandel et al., Quémart \& Lambert; Ronnenberg \& Torrance), and writing pressure (Afonso et al.). The number of variables tracked in this issue demonstrates the richness and diversity of possible variables.

In addition to temporal indicators, it is important to set up methods adapted to the specificity of word writing research. In this issue, Bonin et al. have studied the impact of image characteristics in a picture-writing task. They show that the use of color versus grayscale images influences writing latency.

Studies on word writing can investigate handwriting as well as keyboarding. Several American states have chosen to abandon handwriting lessons in favor of exclusive keyboarding lessons at school, and other countries are currently considering the possibility of making this change in school curricula. The scientific arguments for or against this option are therefore decisive. Although handwriting provides added value for literacy (Longcamp, Zerbato-Poudou, \& Velay, 2005), studies that address this issue from an educational perspective are few. Kindergartners tend to benefit more from handwriting training than typing training when they are subsequently asked to perform a word writing task (Kiefer et al., 2015), suggesting that handwriting is a better way than keyboarding to memorize spelling sequences at the very beginning of learning. However, the influence of low-level automaticity on writing skills has been evidenced for both handwriting and keyboarding, and a lack of fluency with a pen or keyboard leads to difficulties in text production (Beers, Mickail, Abbott, \& Berninger, 2017; Graham \& Harris, 2016). In an environment where written production is mostly achieved through keyboarding, the place of keyboarding 
learning in school to enable students to achieve sufficient keyboard typing skills has to be questioned. In this issue, Feng, Linder, Ryan, \& Joshi conducted a metaanalysis on the impact of keyboarding and handwriting skills and their contribution to writing performance. They showed that primary school children write faster and produce larger quantities of writing under the keyboarding mode than under the handwriting mode. They related this result to previous research that showed that most students write faster with keyboards. The importance of keyboarding fluency has also been evidenced by Ronnenberg and Torrance in sixth graders (this issue). Word spelling accuracy is predicted by key-finding response time, an indicator of keyboard skill automatization. Therefore, the key factor seems to be low-level automaticity rather than the mode of written language production.

\section{Which model for word writing?}

Word writing research involves the study of two essential processes, spelling processing and graphomotor processing. Spelling processes refer to the cognitive mechanisms by which words are transcribed into written form while adhering to the orthographic norms of the language. Graphomotor processing is generally defined as the processes involved in letter writing: allographic selection, allograph adaptation in writing support and muscle adjustment of motor programs (Van Galen, 1990). In a cascade model perspective, most studies assume that the processing of one level has a significant impact on the lower level. For example, significant spelling difficulties do have repercussions for handwriting performance (e.g., Sumner, Connelly, \& Barnett, 2014). This approach requires two assumptions. First, spelling and graphomotor processes interact; that is, they do not function in an encapsulated manner. Therefore, the cognitive demands of one influence the efficiency of the second. The interaction between the different writing processes was proposed in van Galen's (1990) cascading model. The second assumption is the coordination of spelling and graphomotor processes, which makes it possible to accommodate their respective constraints. If the demands on cognitive resources are too high, this will influence the other processes. If this assumption is obvious for high-level processes related to text writing, then for handwriting, it is possible that processes are too automatized. To test this hypothesis, studies can investigate either (1) the impact of spelling complexity on handwriting by comparing, for example, regular and irregular word spelling (Delattre et al., 2006; Roux et al., 2013) or the influence of phonological processing on writing (Damian \& Qu, 2013, Zhang \& Damian, 2010) or (2) the impact of the constraints of handwriting (e.g., letter case) on spelling performance (e.g., Sausset, Lambert, Olive, \& Larocque, 2012).

These so-called "cascade effect" are reported several times in this special issue.

Afonso et al. showed that word consistency affects the dynamics of written word production in different groups of participants (young adults, patients with MCI and patients with Alzheimer's disease), which confirms a cascading influence from central to peripheral processes. Kandel et al. (this issue) also provided arguments in favor of cascading processes. In Kandel et al.'s study, English- and Italian-speaking adults were asked to copy words with and without doublets (e.g., DISSIPATE vs. 
DISGRACE). The time needed to write the last letter of the triplet (e.g., $\mathrm{S}$ in DIS) was faster when this letter was followed by the same letter than not. In addition, the interval between the third and fourth letters was shorter when these two letters were identical. These results suggest that orthographic representations remain activated during word writing and regulate movement execution. Similarly, using a spellingto-dictation task, Planton et al. (this issue) observed that consistency effects on writing latency and writing speed are modulated by word length and by the position of the inconsistency in the word.

Cascade effects are also observed in children. Quémart and Lambert (this issue) showed that French-speaking sixth graders are influenced by the morphological structure of words during handwriting, suggesting that they activate morphological representations when performing the task. Writing duration of the same letter at the same position is indeed influenced by the status of this letter: When it corresponds to the last letter of the word root (e.g., $\mathrm{M}$ in FERMIER), writing duration is longer than when it does not have this status (e.g., $\mathrm{M}$ in FORMULE). The activation of morphological representations is an argument of cascaded processing in children. In line with this result, Ronnenberg and Torrance (this issue) showed the cascade effects of central processes on keyboarding in Norwegian-speaking sixth graders. Words with spelling complexity (e.g., irregular words) were typed faster than words with no spelling challenge. This suggests that words that include orthographic complexities involve an additional processing cost that is reflected during word writing. Once again, this interaction between central and peripheral processes is in line with a cascading view.

\section{Which processing units are relevant to word writing?}

In parallel with the determination of a cognitive model, research on word writing aims to specify the processing unit for each of the cognitive processes involved. Most studies have shown that the letter is the unit of the graphomotor system (Van Mier \& Hulstijn, 1993). The strokes to be produced and their sequence would be recovered in a single block and aggregated to build letter units via a chunking phenomenon (Teulings \& Schomaker, 1993).

The nature of the processing units activated during central processing (i.e., spelling activation) is also debated. Among the possible units, the syllable has received special attention (Kandel, Peereman, Grosjacques, \& Fayol, 2011; Sausset, Lambert, \& Olive, 2016 for a review). Although the syllable is oral in nature, some studies have investigated the intervention of the syllable in written language. In fact, if written language is considered an "overlay" to oral language, then the units involved in one should also influence the other. The syllable, at least in French, is a privileged unit activated to access the lexicon during spoken word recognition (Mahé, Bonnefond, \& Doignon-Camus, 2013) and visual word recognition (Chetail \& Mathey, 2009) via the selection of potential lexical candidates sharing the same first syllable (Conrad, Grainger, \& Jacobs, 2007). The syllable is also perceived as a potential processing unit in written production. First, the syllabic structure of a word influences the dynamics of writing. Movement durations-i.e., inter-letter intervals, such 
as the time period between the letters $A$ and $\mathrm{R}$ in French words such as PAROLE and PARDON - are longer when a syllable boundary falls between the two letters (e.g., PA.ROLE) than when the two fall on the same side of a syllable boundary (e.g., PARDON) (in typing: Kreiner, Price, \& Gross, 2008; Service \& Turpeinen, 2001; in handwriting: Álvarez, Cottrell, \& Afonso, 2009; Kandel \& Valdois, 2006). Second, the number of syllables of a word also plays a significant role in its latency (Lambert, Kandel, Fayol, \& Espéret, 2008): the more syllables a word contains, the longer its latency. Many results therefore converge towards the idea of a syllable as a processing unit in word writing production.

Although there is now a relative consensus on the role of the syllable in handwriting, the precise nature of this unit is still under debate. Some authors have provided arguments in favor of a processing unit based exclusively on oral language (Luria, 1970), while others have shown that the activation of syllabic units is based on graphemes rather than on phonological constituents (Lambert, Sausset, \& Rigalleau, 2015). With the learning to write, it is indeed conceivable that a specific unit of written language becomes autonomous from the constraints of oral language and is gradually constructed. For example, the analysis of the performance of patients with impaired orthographic working memory shows that their error rate is more related to the number of graphemes per syllable than to their phonological complexity (Caramazza \& Miceli, 1990; Ward \& Romani, 2000). To interpret this result, the notion of orthosyllable was defined as follows: a syllabic unit organized around graphemes and having a structure similar to the structure of phonological syllables, notably in terms of alternating consonants and vowels. The orthosyllable is defined as a unit containing all the letters of the syllable, including the silent letters (e.g. /niff/is composed of one syllable CVC vs. KNI.FE, is composed of two orthosyllables CCV. CV). Lambert et al. (2015) have shown that the presence of a silent $E$ in a French word modifies the dynamic of the writing. This suggests that the syllables activated during written word production are specific to written language.

Beyond the syllable, other units are likely to intervene in writing words. In this issue, Kandel et al. investigated the role of bigrams and, more particularly, geminate letters as processing units. According to the authors, these letters are coded at a specific level of representation that is distinct from that of bigrams. Following an article published in 2013 with English-speaking writers (Kandel, Peereman, \& Ghimenton, 2013), the authors show here that, in Italian, the same letter is processed differently if it is part of a geminated letter than if it is not. This result therefore suggests that doublets have a specific status in the production of written words, and it is an argument in favor of a particular encoding of doubled letters. A logographemic representational level has also been postulated in Mandarin (Chen \& Cherng, 2013; Law \& Leung, 2000). In their paper, Damian and $Q u$ (this issue) questioned the logographeme as a processing unit through an implicit priming task. They showed that the radical structure of words influences priming effects but found only weak logographemically based priming effects. Finally, the morpheme could also structure orthographic representations in the orthographic lexicon (Badecker, Hillis, \& Caramazza, 1990). Kandel, Spinelli, Tremblay, Guerassimovitch, and Álvarez (2012) showed that the morphological structure of words influences the dynamics of word writing in adults. Quémart and Lambert (this issue) replicated this effect 
in adults and showed that the morphological complexity of words influences the dynamics of writing from the fourth grade. Morphological processing slows down handwriting either at the syllabic boundary (in fourth graders) or at the morphemic boundary (in sixth graders). Taken together, these results indicate that the cognitive processes involved in word writing involve different units: graphemes, syllables and morphemes.

\section{What model for lifespan word writing skills?}

The points of attention raised so far can also be questioned at the developmental level for both typical and atypical development. The first issue is the relation between central and peripheral processes when producing written words. The links between graphomotor development and text production have been widely explored (e.g., Swanson \& Berninger, 1996). The capacity approach of working memory postulates that cognitive resources are shared between different processes and that the cost of a process is a function of its degree of automatization (McCutchen, 1996). If there are constraints on low-level processes such as graphomotor processes, highlevel processes may not be properly activated due to lack of resources. At the beginning of learning, by definition, low-level processes (handwriting and keyboarding) are not yet automatized, and therefore, their resource demands will be at the expense of higher-level processes involved in text production (planning, revision; Olive \& Kellogg, 2002). Graham, Berninger, Abbott, Abbott, and Whitaker (1997) estimated that handwriting fluency accounts for $60 \%$ of the variance in writing quality in the first grade and $40 \%$ in the fourth grade. This link is still significant after 6 years of learning (Medwell, Strand, \& Wray, 2009), and it is even significant for university students who write in situations under time pressure (Connelly, Dockrell, \& Barnett, 2005).

However, very few studies have focused on the evolution of the links between graphomotor processing and spelling during the learning of writing. If children are able to activate low-level and high-level processes in parallel, their writing movements should be influenced by cognitive processes (as observed in adults, e.g., Delattre et al., 2006). The first arguments in favor of a cascade from central to peripheral processes were reported by Kandel and Perret (2015). They showed that handwriting duration and fluency are influenced by sublexical (i.e., consistency) and lexical (i.e., frequency) variables from the age of 8 . In this issue, Ronnenberg et al. present new evidence that spelling processes cascade into movement production in children during a typing task. Using a spelling-to-dictation task on the keyboard, they found that Norwegian 6th graders are influenced by spelling complexity (i.e., word inconsistencies) beyond typing onset. This result suggests that mapping of phonemes onto graphemes as an application of phoneme-grapheme correspondences cascades during typing.

The second point to be raised at the developmental level concerns the processing units. The syllable is a processing unit involved in children's word writing. For example, the syllabic boundary is a privileged place to return to the model during a word copy task (Transler, Leybaert, \& Gombert, 1999). In a polysyllabic word, 
children in 3rd, 4th, and 5th grades take longer to write the first letter of the second syllable than to write the other letters (Bogaerts, Meulenbroek, \& Thomassen, 1996; Kandel, Hérault, Grosjacques, Lambert, \& Fayol, 2009; Kandel \& Valdois, 2006). Thus, the preparation of the first syllable of the word is completed before the beginning of the execution, and the preparation of the second syllable occurs during the handwriting of the first letter of that syllable.

The morpheme is also a candidate as a processing unit of word writing in children. Kandel et al. (2012) showed that adult writers pause longer between two letters when these two letters belong to different morphemes (e.g., between the L and the $\mathrm{E}$ in VOLEUR) than when they belong to the same morpheme (e.g., between the $\mathrm{L}$ and the $\mathrm{E}$ in SOLEIL). This result suggests that adults activate the second morpheme when they finish writing the first one. This result has been replicated by Quémart and Lambert (this issue). In their study, they extended this result by showing that the morpheme is a processing unit activated from 4th grade on and that the locus of activation of this unit is different in 4th graders (at the syllabic boundary) and in 6th graders up through adulthood (at the morphemic boundary).

The other extreme of development concerns aging. Afonso et al. (this issue) report, for the first time, data on the way normal aging adults and patients with dementia (MCI and Alzheimer's disease) deal with central and peripheral processes when writing. The study of word writing in people with particular diseases makes it possible, first, to better understand the processes affected by the disease and, second, to have information on the evolution of the disease itself. In their study, Afonso et al. showed that writing abilities are affected in persons with mild stages of the disease compared to healthy seniors. The writing difficulties of patients with Alzheimer's disease are present at both the central and peripheral levels, while those of patients with MCI are present only at the central level. However, patients show consistency effects on latency and inter-letter duration similar to those of controls, suggesting that these two levels of processing are still in interaction in patients with dementia. Thus, the deterioration of peripheral processes of handwriting could be an indicator of the progress of disease in patients with Alzheimer's disease.

\section{Can research results on word writing be considered universal?}

The study of word writing also requires taking into account the languages and, more specifically, the orthographic systems that are studied. Orthographic writing systems differ in the way they represent phonological, orthographic and morphological information. For example, the role of phonological codes in writing appears to depend on the language studied: Phonological information is activated when processing Spanish orthography (Afonso \& Álvarez, 2011) but not when processing English orthography (Shen, Damian, \& Stadthagen-Gonzalez, 2013). This may be related to the specificities of the two spelling systems and, more particularly, to their level of orthographic consistency.

Likewise, the role of the syllable does not appear to be similar in all languages. The syllabic complexity effect found in the Italian patient LB (Caramazza \& Miceli, 1990) was not observed in English-speaking patients (Badecker, 1996; 
Ward \& Romani, 2000). The links between phonological and spelling codes is not universal but dependent on the specificities of each language's spelling system.

Kandel et al. (this issue) explored this question of the universality of the processing involved in word writing by comparing two languages: English and Italian. Their objective was to determine if double letters are processed as a single unit (i.e., chunked into a larger unit) or as separate units. The Italian language constitutes an interesting case to investigate this issue since, in contrast to English, Italian letter doublets have a phonological counterpart corresponding to germination (i.e., lengthening in the realization of the consonant with respect to a single consonant). This comparison thus makes it possible to provide arguments concerning the influence of phonological representations in written word production. The results revealed that the presence of doublets in a word affects the timing of writing. Cross-linguistic differences were nonetheless observed: the impact of doublets on word writing was larger in Italian than in English.

In languages with an alphabetic system of orthography, the sequence of letters in the word almost systematically provides phonological information, and precisely dissociating the effects of phonological and orthographic codes is almost always impossible. This link is important in shallow orthography, such as Italian, but even for deeper orthography, such as French or English. With an alphabetic system, there is always at least a partial relationship between phonology and spelling. It follows that the dissociation of the respective influences of phonological and orthographic codes is not always easy to operationalize.

On the other hand, Mandarin allows for fully distinguishing between phonological and orthographic codes. For instance, two different characters may have the same phonology (but with only a different tone), and two characters with common graphic traits may be pronounced in totally different ways $(\mathrm{Qu}, \mathrm{Damian}$, $\& \mathrm{Li}, 2016)$. Using a priming paradigm, Zhang and Wang (2015) succeeded in dissociating orthographic and phonological priming and showed that only orthographic priming facilitates writing latency. In this issue, Damian \& $Q u$ attempt to determine the orthographic Mandarin-specific processing unit. Chinese characters are composed of radicals that themselves contain strokes. Between the radical and the strokes, some studies have shown the existence of a logographemic representation. Their study showed that the radical intervenes, as a processing unit, while the logographeme does not seem to play a significant role.

All the papers in this special issue demonstrate both the diversity and richness of studies devoted to word writing and the vitality of the field through complementary research from different countries. Although there are still many questions to be explored in the years to come (which will be helpful), the results presented here allow us to present a coherent scientific review. We hope that this special issue can encourage and inspire young researchers.

Acknowledgements We thank Thierry Olive for helpful comments on previous versions of the manuscript. 


\section{References}

Afonso, O., \& Alvarez, C. (in press). Measuring writing durations in handwriting research: What do they tell us about the spelling process? In C. Perret \& T. Olive (Eds), Spelling and writing words: Theoretical and methodological advances. Leiden/Boston: Brill.

Afonso, O., \& Álvarez, C. J. (2011). Phonological effects in handwriting production: Evidence from the implicit priming paradigm. Journal of Experimental Psychology. Learning, Memory, and Cognition, 37, 1474-1483.

Alamargot, D., Chesnet, D., Dansac, C., \& Ros, C. (2006). Eye and pen: A new device for studying reading during writing. Behavior Research Methods, 38, 287-299.

Álvarez, C. J., Cottrell, D., \& Afonso, O. (2009). Writing dictated words and picture names: Syllabic boundaries affect execution in Spanish. Applied Psycholinguistics, 30, 205-223.

Badecker, W. (1996). Representational properties common to phonological and orthographic output systems. Lingua, 99, 55-83.

Badecker, W., Hillis, A., \& Caramazza, A. (1990). Lexical morphology and its role in the writing process: Evidence from a case of acquired dysgraphia. Cognition, 35, 205-243.

Bazerman, C. (Ed.). (2009). Handbook of research on writing: History, society, school, individual, text. London: Routledge.

Beers, S. F., Mickail, T., Abbott, R., \& Berninger, V. (2017). Effects of transcription ability and transcription mode on translation: Evidence from written compositions, language bursts and pauses when students in grades 4 to 9, with and without persisting dyslexia or dysgraphia, compose by pen or by keyboard. Journal of Writing Research, 9, 1-25.

Bogaerts, H., Meulenbroek, R. G. J., \& Thomassen, A. J. W. M. (1996). The possible role of the syllable as a processing unit in handwriting. In M. L. Simner, C. G. Leedham, \& A. J. W. M. Thomassen (Eds.), Handwriting and drawing research: Basic and applied issues (pp. 115-126). Amsterdam: IOS Press.

Bonin, P., Fayol, M., \& Peereman, R. (1998). Masked form priming in writing words from pictures: Evidence for direct retrieval of orthographic codes. Acta Psychologica, 99, 311-328.

Caramazza, A., \& Miceli, G. (1990). The structure of graphemic representations. Cognition, 37, 243-297.

Chen, J. Y., \& Cherng, R. J. (2013). The proximate unit in Chinese handwritten character production. Frontiers in Psychology, 4(517), 10-3389.

Chetail, F., \& Mathey, S. (2009). Syllabic priming in lexical decision and naming tasks: The syllable congruency effect re-examined in French. Canadian Journal of Experimental Psychology, 63, 40-48.

Connelly, V., Dockrell, J. E., \& Barnett, J. (2005). The slow handwriting of undergraduate students constrains overall performance in exam essays. Educational Psychology, 25, 99-107.

Conrad, M., Grainger, J., \& Jacobs, A. M. (2007). Phonology as the source of syllable frequency effects in visual word recognition: Evidence from French. Memory \& Cognition, 35(5), 974-983.

Damian, M. F., \& Qu, Q. Q. (2013). Is handwriting constrained by phonology? Evidence from Stroop tasks with written responses and Chinese characters. Frontiers in Psychology, 4, 765.

Delattre, M., Bonin, P., \& Barry, C. (2006). Written spelling to dictation: Sound-to-spelling regularity affects both writing latencies and durations. Journal of Experimental Psychology. Learning, Memory, and Cognition, 32, 1330-1340.

Ellis, A. W. (1979). Slips of the pen. Visible Language, 13, 265.

Graham, S., Berninger, V. W., Abbott, R. D., Abbott, S. P., \& Whitaker, D. (1997). Role of mechanics in composing of elementary school students: A new methodological approach. Journal of Educational Psychology, 89, 170-182.

Graham, S., \& Harris, K. R. (2016). A path to better writing. The Reading Teacher, 69(4), 359-365.

Guinet, E., \& Kandel, S. (2010). Ductus: A software package for the study of handwriting production. Behavior Research Methods, 42, 326-332.

Henderson, E. H., \& Beers, J. W. (1980). Developmental and cognitive aspects of learning to spell: A reflection of word knowledge. Newark: International Reading Association.

Kandel, S., Hérault, L., Grosjacques, G., Lambert, E., \& Fayol, M. (2009). Orthographic vs. phonologic syllables in handwriting production. Cognition, 110, 440-444.

Kandel, S., Peereman, R., \& Ghimenton, A. (2013). Further evidence for the interaction of central and peripheral processes: The impact of double letters in writing English words. Frontiers in psychology, 4, 729 . 
Kandel, S., Peereman, R., Grosjacques, G., \& Fayol, M. (2011). For a psycholinguistic model of handwriting production: Testing the syllable-bigram controversy. Journal of Experimental Psychology: Human Perception and Performance, 37(4), 1310.

Kandel, S., \& Perret, C. (2015). How does the interaction between spelling and motor processes build up during writing acquisition? Cognition, 136, 325-336.

Kandel, S., Spinelli, E., Tremblay, A., Guerassimovitch, H., \& Álvarez, C. J. (2012). Processing prefixes and suffixes in handwriting production. Acta Psychologica, 140(3), 187-195.

Kandel, S., \& Valdois, S. (2006). Syllables as functional units in a copying task. Language and Cognitive Processes, 21, 432-452.

Kiefer, M., Schuler, S., Mayer, C., Trumpp, N. M., Hille, K., \& Sachse, S. (2015). Handwriting or typewriting? The influence of pen-or keyboard-based writing training on reading and writing performance in preschool children. Advances in Cognitive Psychology, 11, 136-146.

Kreiner, D. S., Price, R. Z., \& Gross, A. M. (2008). Linguistic boundaries as predictors of the time between letters in oral and typed spellings. The Journal of General Psychology, 135, 117-132.

Lambert, E., Kandel, S., Fayol, M., \& Espéret, E. (2008). The effect of the number of syllables on handwriting production. Reading and Writing, 21, 859-883.

Lambert, E., Sausset, S., \& Rigalleau, F. (2015). The ortho-syllable as a processing unit in handwriting: The mute e effect. Reading and Writing, 28, 683-698.

Law, S. P., \& Leung, M. T. (2000). Structural representations of characters in Chinese writing: Evidence from a case of acquired dysgraphia. Psychologia, 43, 67-83.

Longcamp, M., Zerbato-Poudou, M. T., \& Velay, J. L. (2005). The influence of writing practice on letter recognition in preschool children: A comparison between handwriting and typing. Acta Psychologica, 119, 67-79.

Luria, A. R. (1970). Traumatic aphasia. The Hague: Mouton.

Mahé, G., Bonnefond, A., \& Doignon-Camus, N. (2013). The time course of the syllable frequency effect in visual word recognition: Evidence for both facilitatory and inhibitory effects in French. Reading and Writing, 27, 171-187.

McCutchen, D. (1996). A capacity theory of writing: Working memory in composition. Educational Psychology Review, 8, 299-325.

Medwell, J., Strand, S., \& Wray, D. (2009). The links between handwriting and composing for Y6 children. Cambridge journal of education, 39(3), 329-344.

Neuroscript. (2018). MovAlyzeR. http://www.neuroscript.net/movalyzer.php. Accessed June 2018.

Olive, T. (2014). Toward an incremental and cascading model of writing: A review of research on writing processes coordination. Journal of Writing Research, 6, 173-194.

Olive, T., \& Kellogg, R. T. (2002). Concurrent activation of high-and low-level production processes in written composition. Memory \& Cognition, 30, 594-600.

Qu, Q. Q., Damian, M. F., \& Li, X. (2016). Phonology contributes to writing: Evidence from a masked priming task. Language, Cognition, and Neuroscience, 31, 251-264.

Roux, S., \& Bonin, P. (2011). Cascaded processing in written naming: Evidence from the picture-picture interference paradigm. Language and Cognitive Processes, 27, 734-769.

Roux, S., McKeeff, T. J., Grosjacques, G., Afonso, O., \& Kandel, S. (2013). The interaction between central and peripheral processes in handwriting production. Cognition, 127, 235-241.

Sausset, S., Lambert, E., \& Olive, T. (2016). La syllabe dans la production écrite de mots. L'Année Psychologique, 116, 137-169.

Sausset, S., Lambert, E., Olive, T., \& Larocque, D. (2012). Processing of syllables during handwriting: Effects of graphomotor constraints. The Quarterly Journal of Experimental Psychology, 65, $1872-1879$.

Service, E., \& Turpeinen, R. (2001). Working memory in spelling: Evidence from backward typing. Memory, 9, 395-421.

Shen, X. R., Damian, M. F., \& Stadthagen-Gonzalez, H. (2013). Abstract graphemic representations support preparation of handwritten responses. Journal of Memory and Language, 68, 69-84.

Sumner, E., Connelly, V., \& Barnett, A. L. (2014). The influence of spelling ability on handwriting production: Children with and without dyslexia. Journal of Experimental Psychology. Learning, Memory, and Cognition, 40, 1441-1447.

Swanson, H. L., \& Berninger, V. W. (1996). Individual differences in children's working memory and writing skill. Journal of Experimental Child Psychology, 63(2), 358-385.

Teulings, H. L., \& Schomaker, L. R. B. (1993). Invariant properties between stroke features in handwriting. Acta Psychologica, 82, 69-88. 
Transler, C., Leybaert, J., \& Gombert, J. (1999). Do deaf children use phonological syllables as reading units? Journal of Deaf Studies and Deaf Education, 4, 124-143.

Van Galen, G. P. (1990). Phonological and motoric demands in handwriting: Evidence for discrete transmission of information. Acta Psychologica, 74, 259-275.

Van Mier, H., \& Hulstijn, W. (1993). The effects of motor complexity and practice on initiation time in writing and drawing. Acta Psychologica, 84, 231-251.

Ward, J., \& Romani, C. (2000). Consonant-vowel encoding and orthosyllables in a case of acquired dysgraphia. Cognitive Neuropsychology, 17, 641-663.

Zhang, Q., \& Damian, M. F. (2010). Impact of phonology on the generation of handwritten responses: Evidence from picture-word interference tasks. Memory \& cognition, 38, 519-528.

Zhang, Q., \& Wang, C. (2015). Phonology is not accessed earlier than orthography in Chinese written production: Evidence for the orthography autonomy hypothesis. Frontiers in psychology, 6, 448. 